\title{
Age of menarche and near adult height after long-term gonadotropin-releasing hormone agonist treatment in girls with central precocious puberty
}

\author{
Joon-Woo Baek, MD', \\ Hyo-Kyoung Nam, MD, PhD', \\ Dahee Jin, MD', \\ Yeon Joung Oh, $\mathrm{MD}^{2}$, \\ Young-Jun Rhie, MD, PhD', \\ Kee-Hyoung Lee, MD, $\mathrm{PhD}^{1}$ \\ ${ }^{1}$ Department of Pediatrics, Korea \\ University College of Medicine, \\ Seoul, ${ }^{2}$ Department of Pediatrics, \\ Hallym University Kangnam Sacred \\ Heart Hospital, Seoul, Korea
}

Purpose: Gonadotropin-releasing hormone agonist (GnRHa) is known for improving final adult height in patients with central precocious puberty (CPP). This study aimed to investigate the age of menarche and near adult height in girls with CPP who had been treated with GnRHa.

Methods: In this retrospective study, we reviewed the medical records of 71 Korean girls with CPP who had started menarche or reached over 13 years of bone age after long-term GnRHa treatment. We estimated near adult height using the BayleyPinneau method and identified the age of menarche in girls with CPP.

Results: Mean chronological and bone age at menarche were $11.9 \pm 0.7$ and $12.8 \pm 0.4$ years, respectively. The period between menarche and the end of treatment was $14.0 \pm 5.6$ months. Posttreatment near adult height was $163.8 \pm 4.7 \mathrm{~cm}$, which was significantly greater than pretreatment predicted adult height $(158.7 \pm 4.1 \mathrm{~cm})$.

Conclusion: GnRHa treatment in girls with CPP could improve final adult height and made the age of menarche close to that of the general population.

Keywords: Gonadotropin-releasing hormone, Precocious puberty, Central, Menarche
Received: 3 March, 2014

Revised: 19 March, 2014

Accepted: 24 March, 2014

Address for correspondence:

Kee-Hyoung Lee, MD

Department of Pediatrics, Korea

University College of Medicine, 73

Inchon-ro, Seongbuk-gu, Seoul

136-705, Korea

Tel: +82-2-920-6604

Fax: +82-2-922-7476

E-mail: khlee218@kumc.or.kr

\section{Introduction}

Central precocious puberty (CPP) is defined as the onset of secondary sexual characteristics before the age of 8 years for girls and 9 years for boys, which is usually due to the premature activation of the hypothalamic-pituitary-ovarian axis (H-P-G axis $)^{1)}$. Early diagnosis and treatment of CPP is important to improve final height because CPP can cause early epiphyseal maturation with compromised final height as well as psychological stress ${ }^{2,3)}$.

Gonadotropin-releasing hormone agonist ( $\mathrm{GnRHa}$ ) is constantly combined to gonadotropin-releasing hormone receptor of pituitary gland, which is known as a safe and effective treatment for controlling premature H-P-G axis activation. Several studies reported that GnRHa treatment in CPP improved predicted adult height (PAH) in the target height range ${ }^{4-8)}$. However, there were a few reports about the age of menarche or final adult height after GnRHa treatment because of difficulties with continuous follow-up observation after the end of treatment.

The aim of this study was to investigate the age of menarche and near adult height in girls with CPP who had been treated with GnRHa.

\section{Materials and methods}

\section{Subjects}

In this retrospective study, we reviewed the medical records of 71 Korean girls with CPP, 
from March 2003 to February 2011 at a pediatric endocrinology clinic of Korea University Hospital. All subjects were treated with GnRHa and they had showed menarche or reached over 13 years of bone age (BA) after GnRHa treatment.

CPP was diagnosed by the appearance of secondary sexual maturation under the age of 8 years, BA advancement, and a pubertal peak luteinizing hormone level $\geq 5$ IU/L. To exclude other forms of precocious puberty, further laboratory and imaging studies were performed based on clinical judgment. CPP patients with identified etiology, such as brain tumor or cranial irradiation, were excluded.

\section{Methods}

All patients were injected with leuprolide acetate, 75-100 $\mu \mathrm{g} / \mathrm{kg}$ every 4 weeks and height, weight, and degree of pubertal development were checked. After GnRHa treatment, the patients regularly followed every 3 months to observe the changes of height, sexual maturity and menarche.

Their BAs were evaluated every six months by taking the left hand $\mathrm{x}$-ray. BA was assessed by two pediatric endocrinologists using the Greulich-Pyle method, and PAH was estimated using the Bayley-Pinneau method ${ }^{9)}$.

For the comparison with auxological parameters at the onset of GnRHa treatment, subjects were divided into three groups: $<8$ years, $8-9$ years, and $9-10$ years.

\section{Statistical analyses}

Statistical analyses were performed using IBM SPSS version 20.0 (IBM Co., Armonk, NY, USA). Multiple linear regression analysis was used for measuring the association of multiple clinical factors on PAH. The comparison among three groups mentioned before was applied using analysis of variance. All data were expressed as means \pm standard deviation. The $P$-value of $<0.05$ was considered as statistically significant.

\section{Results}

\section{Comparison of clinical and auxological characteristics of subjects between at the start of the treatment and at the last visit after the treatment}

At the start of GnRHa treatment, the mean chronological age

Table 1. Auxological data of subjects $(\mathbf{n}=71)$

\begin{tabular}{lccc}
\hline Variable & Before treatment & Last visit & $P$-value \\
\hline Mean CA (yr) & $8.5 \pm 0.7$ & $12.3 \pm 0.8$ & $<0.001$ \\
Mean BA (yr) & $10.4 \pm 0.8$ & $13.5 \pm 0.6$ & $<0.001$ \\
Mean BA-CA (yr) & $1.9 \pm 1.2$ & $1.2 \pm 1.0$ & $<0.001$ \\
MPH (cm) & $161.6 \pm 3.6$ & & \\
PAH (cm) & $158.7 \pm 4.1$ & $163.8 \pm 4.7$ & $<0.001$ \\
Height-SDS for CA & $1.63 \pm 0.77$ & $1.18 \pm 0.81$ & 0.482 \\
Height-SDS for BA & $-0.35 \pm 0.53$ & $0.65 \pm 0.78$ & 0.136 \\
\hline
\end{tabular}

Values are presented as mean \pm standard deviation.

$\mathrm{CA}$, chronological age; $\mathrm{BA}$, bone age, $\mathrm{MPH}$, mid parental height; $\mathrm{PAH}$, predicated adult height; SDS, standard deviation score.
(CA) and BA were $8.5 \pm 0.7$ and $10.4 \pm 0.8$ years, respectively. The difference between BA and CA was $1.9 \pm 1.2$ years. At the last visit after treatment, the mean $\mathrm{CA}$ and $\mathrm{BA}$ was $12.3 \pm 0.8$ and $13.5 \pm 0.6$ years. The difference between BA and CA decreased to $1.2 \pm 1.0$ years. The mean mid parent height $(\mathrm{MPH})$ was $161.6 \pm 3.6 \mathrm{~cm}$. The near adult height at the last visit was taller than pretreatment PAH $(163.8 \pm 4.7 \mathrm{~cm}$ vs. $158.7 \pm 4.1 \mathrm{~cm})$. Mean height standard deviation score (SDS) for CA and BA showed no significant differences between at the start of the treatment and at the last visit after the treatment (Table 1).

\section{Duration of the treatment and the age of menarche}

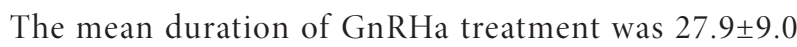
months. The time interval from the end of the treatment to menarche was $14.0 \pm 5.6$ months. The mean CA and BA at menarche of 52 girls who started the menarche were $11.9 \pm 0.7$ and $12.8 \pm 0.4$ years, respectively (Table 2 ). The time interval of menarche after the end of treatment was not correlated with any other factors (duration of treatment, CA at the end of GnRHa, $\mathrm{BA}$ at the end of GnRHa, height at the end of GnRHa) by using simple linear regression analysis.

\section{Comparison of PAH according to the age at the onset of GnRHa treatment}

Subjects were divided into three groups to observe the difference of PAH and the age of menarche according to the age at onset of GnRHa treatment: $<8$ years, $8-9$ years, 9-10 years. There were no significant differences in the period between menarche and the end of treatment among the three groups. The trend showed that the more treatment is delayed the less PAH increases: $5.9 \pm 3.7 \mathrm{~cm}, 4.8 \pm 2.9 \mathrm{~cm}, 3.8 \pm 2.3 \mathrm{~cm}$, respectively. However, there was no significant difference among the three groups $(P=0.095)$ (Table 3).

\section{The correlation between near adult height and other auxological factors}

Univariate analysis using simple linear regression was performed for correlation between near adult height and other auxological factors. Near adult height was significantly correlated with MPH $(P<0.001)$, BA-CA at start $(P=0.024)$,

Table 2. Time of menarche and duration of treatment $(n=52)$

\begin{tabular}{|c|c|}
\hline Variable & Mean $\pm S D$ \\
\hline Duration of treatment (mo) & $27.9 \pm 9.0$ \\
\hline CA at the end of treatment (yr) & $10.8 \pm 0.5$ \\
\hline BA at the end of treatment (yr) & $11.8 \pm 0.4$ \\
\hline CA at menarche (yr) & $11.9 \pm 0.7$ \\
\hline BA at menarche (yr) & $12.8 \pm 0.4$ \\
\hline Menarche after $\mathrm{GnRH}^{\mathrm{a})}$ (mo) & $14.0 \pm 5.6$ \\
\hline
\end{tabular}

SD, standard deviation; CA, Chronological age; BA, Bone age; GnRHa, gonadotropin-releasing hormone agonist.

a) Time interval from the end of the treatment to menarche. 
PAH at start $(P<0.001)$, PAH after treatment $(P<0.001)$, height SDS for BA at onset of treatment $(P<0.001)$, and height SDS for BA after treatment $(P<0.001)$. Near adult height was not correlated with duration of treatment, CA or BA at start. After multicollinearity checking among explanatory variables (MPH, BA-CA at start, PAH at start, PAH after treatment, height SDS for BA at start, height SDS for BA after GnRHa), a multivariate analysis using multiple linear regression revealed MPH and PAH after treatment were independently correlated with near adult height (Table 4).

\section{Discussion}

This study is about the comparison of pretreatment PAH and adult height after the GnRHa treatment and investigation of actual age of menarche. The results of this study showed that long-term GnRHa treatment improved final height in girls with CPP.We also found that the age of menarche in girls treated with GnRHa was comparable to that of the general population ${ }^{10)}$.

CPP in girls is defined as the appearance of secondary sex characteristics before the age of 8 years due to premature activation of the H-P-G axis. Idiopathic CPP excludes precocious puberty caused by specific conditions, for example, structural brain lesions, thyroid disorders, diabetes, chronic renal failure, and congenital adrenal hyperplasia. The secretion of growth hormone and insulin-like growth factor-I is augmented by sex hormone stimulation. The rate of growth and bone maturation is also rapidly increased. That leads to short final adult height.

After GnRHa treatment, the patients need follow up to observe the changes of height and sexual maturity. However, there are a few reports regarding the actual age of menarche and final adult height because most patients rarely attend the follow up clinic continuously after GnRHa treatment. In previous studies, to evaluate the effect of treatment intervention, growth velocity or PAH estimation in the short term were generally used $^{4,5)}$. Some author reported on final height of CPP girls too small selected groups ${ }^{8)}$. In this study, we investigated actual age of menarche and measured near adult height with long-term follow-up after GnRHa treatment.

A recent survey showed the age of menarche in Korea is getting younger from 16 years in 1920 s to 12.6 years in $1990 \mathrm{~s}^{10,11)}$. Untreated patients with precocious puberty encountered menarche earlier than the general population. In this study, the mean CA at menarche was 11.9 years and BA was 12.8 years. The age of menarche was comparable to the general population due to the treatment. The time interval from the end of the treatment to menarche was $14.0 \pm 5.6$ months, which was

Table 3. Change in difference of PAH and time of menarche in according to start age of GnRHa treatment

\begin{tabular}{|c|c|c|c|c|}
\hline \multirow{2}{*}{ Variable } & \multicolumn{3}{|c|}{ Start age of GnRHa treatment (yr) } & \multirow{2}{*}{$P$-value } \\
\hline & $<8(n=17)$ & $8-9(n=35)$ & $9-10(n=19)$ & \\
\hline CA at start (yr) & $7.5 \pm 0.5$ & $8.6 \pm 0.3$ & $9.3 \pm 0.1$ & $<0.001$ \\
\hline BA at start (yr) & $9.9 \pm 1.0$ & $10.5 \pm 0.7$ & $10.9 \pm 0.3$ & 0.002 \\
\hline BA-CA at start (yr) & $2.4 \pm 0.7$ & $2.1 \pm 0.7$ & $1.6 \pm 0.3$ & $<0.001$ \\
\hline Menarche after $\mathrm{GnRHa} a^{\mathrm{a})}(\mathrm{mo})$ & $14.4 \pm 4.8$ & $13.3 \pm 5.3$ & $14.4 \pm 3.6$ & 0.766 \\
\hline $\mathrm{MPH}(\mathrm{cm})$ & $161.6 \pm 4.1$ & $161.4 \pm 3.7$ & $162.1 \pm 0.5$ & 0.829 \\
\hline PAH at start $(\mathrm{cm})$ & $158.6 \pm 4.3$ & $158.8 \pm 4.3$ & $159.3 \pm 3.4$ & 0.855 \\
\hline Near adult height (cm) & $164.2 \pm 3.7$ & $163.7 \pm 5.7$ & $163.6 \pm 1.8$ & 0.932 \\
\hline$\triangle \mathrm{PAH}(\mathrm{cm})$ & $5.9 \pm 3.7$ & $4.8 \pm 2.9$ & $3.8 \pm 2.3$ & 0.095 \\
\hline
\end{tabular}

Values are presented as mean \pm standard deviation.

CA, chronological age; BA, bone age; GnRHa, gonadotropin releasing hormone agonist; MPH, mid parental height; PAH, predicated adult height; SDS, standard deviation score; $\triangle \mathrm{PAH}$, PAH difference before and after GnRHa.

a) Time interval from the end of the treatment to menarche.

Table 4. The correlation between near adult height and multiple factors

\begin{tabular}{|c|c|c|c|c|c|c|}
\hline \multirow{2}{*}{ Variable } & \multicolumn{3}{|c|}{ Univariable } & \multicolumn{3}{|c|}{ Multivariable } \\
\hline & Coefficient & SE & $P$-value & Coefficient & SE & $P$-value \\
\hline $\mathrm{MPH}(\mathrm{cm})$ & 0.676 & 0.132 & $<0.001$ & 0.248 & 0.109 & 0.026 \\
\hline CA at start (yr) & -0.256 & 0.779 & 0.743 & & & \\
\hline BA at start (yr) & -1.162 & 0.658 & 0.082 & & & \\
\hline BA-CA at start (yr) & -1.663 & 0.718 & 0.024 & -0.084 & 0.592 & 0.888 \\
\hline PAH at start $(\mathrm{cm})$ & 0.753 & 0.103 & $<0.001$ & 0.196 & 0.135 & 0.152 \\
\hline PAH after treatmet $(\mathrm{cm})$ & 0.810 & 0.073 & $<0.001$ & 0.509 & 0.154 & 0.002 \\
\hline Height SDS for BA at start & 2.665 & 0.463 & $<0.001$ & 0.281 & 0.401 & 0.486 \\
\hline Height SDS for BA after treatmet & 3.402 & 0.384 & $<0.001$ & 0.527 & 0.582 & 0.369 \\
\hline Duration of treatment (mo) & 0.010 & 0.063 & 0.874 & & & \\
\hline
\end{tabular}

SE, standard error; MPH, mid parental height; CA, chronological age; BA, bone age; PAH, predicated adult height; SDS, standard deviation score. 
similar to previous studies ${ }^{12)}$.

According to some reports, adult height after the GnRHa treatment increases although there are some different effects in number ${ }^{13-16)}$. In our study, pretreatment mean BA was 1.9 years advanced compare to mean CA. However, after treatment, the differences decreased to 1.0 years, which means it works well in inhibiting bone maturity. Pretreatment PAH was $158.7 \mathrm{~cm}$, which was only $2.9 \mathrm{~cm}$ shorter than MPH of $161.6 \mathrm{~cm}$, which is the target height in this study. The Bayley-Pinneau method has been used for PAH, although it has been criticized for the methods used to predicted height, as the results were taller than actual adult height ${ }^{17)}$. In addition, for younger children, $\mathrm{PAH}$ is taller than actual height ${ }^{18,19)}$. At the last follow-up after the treatment, we considered that girls reached near adult height at around 13.5 years of BA. Near adult height was $5.1 \mathrm{~cm}$ taller than pretreatment PAH. Consequently, this study verified that GnRHa has a positive effect on adult height.

Patients were divided into three groups, $<8$ years, $8-9$ years, $9-10$ years, to investigate change of PAH by onset age of treatment. However, there was no distinction among three groups. This result differs from a previous report ${ }^{20)}$. It may have been similar if we had investigated a larger number of girls or divided the groups according to age like the previous study. On the other hand, effect on final adult height is not significant if GnRHa treatment begins before 10 years old.

In the previous study, there was a negative correlation between final height and CA or BA at onset of treatment ${ }^{21)}$. Our study also showed negative correlation between near adult height and BA-CA at start $(P=0.024)$. But there was no significant correlation between near adult height and $C A$ at start or BA at start. This may be due to the relatively small sample size. Multiple regression analysis revealed that there were no significant correlation between near adult height an BA-CA at start. Significant variables were only MPH and PAH after treatment.

Through long-term follow-up, we investigated the near adult height of girls with CPP who reached over 13 years of $\mathrm{BA}$ after GnRHa treatment, but this was not the actual final adult height. In a recent study, it was generally known that a girl's growth velocity rapidly decreases after age 13 and then grows only a few centimeters to reach final height ${ }^{22}$. Another possible limitation of this study was that the sample scale was relatively small.

In conclusion, long-term GnRHa treatment could improve final height in girls with CPP, and the age of menarche of girls with GnRHa becomes close to that of the general population. We recommend continuous follow-up of CPP girls after GnRHa treatment to identify the occurrence of menarche and investigate long-term implications for general health status including final adult height.

\section{Conflict of interest}

No potential conflict of interest relevant to this article was reported.

\section{References}

1. Carel JC, Leger J. Clinical practice: precocious puberty. N Engl J Med 2008;358:2366-77.

2. Shankar RR, Pescovitz OH. Precocious puberty. Adv Endocrinol Metab 1995;6:55-89.

3. Bertelloni S, Baroncelli GI, Sorrentino MC, Perri G, Saggese G. Effect of central precocious puberty and gonadotropinreleasing hormone analogue treatment on peak bone mass and final height in females. Eur J Pediatr 1998;157:363-7.

4. Nam HK, Shin JY, Oh YJ, Rhie YJ, Yoo Y, Park SH, et al. The comparison of clinical factors according to growth velocity during gonadotropin-releasing hormone agonist treatment in central precocious puberty girls. Endocrinol Metab 2010;25:206-212.

5. Shin JH, Hu WK, Hwang IT, Yang S. Prediction of 1 year growth in girls with precocious puberty with GnRH agonist treatment by measurement of growth velocity at 3 months after treatment. J Korean Soc Pediatr Endocrinol 2011;16:80-5.

6. Lee PA, Neely EK, Fuqua J, Yang D, Larsen LM, MattiaGoldberg C, et al. Efficacy of leuprolide acetate 1-month depot for central precocious puberty (CPP): growth outcomes during a prospective, longitudinal study. Int J Pediatr Endocrinol 2011;2011:7.

7. Poomthavorn P, Suphasit R, Mahachoklertwattana P. Adult height, body mass index and time of menarche of girls with idiopathic central precocious puberty after gonadotropinreleasing hormone analogue treatment. Gynecol Endocrinol 2011;27:524-8.

8. Paul D, Conte FA, Grumbach MM, Kaplan SL. Long-term effect of gonadotropin-releasing hormone agonist therapy on final and near-final height in 26 children with true precocious puberty treated at a median age of less than 5 years. J Clin Endocrinol Metab 1995;80:546-51.

9. Bayley N, Pinneau SR. Tables for predicting adult height from skeletal age: revised for use with the Greulich-Pyle hand standards. J Pediatr 1952;40:423-41.

10. Ahn JH, Lim SW, Song BS, Seo J, Lee JA, Kim DH, et al. Age at menarche in the Korean female: secular trends and relationship to adulthood body mass index. Ann Pediatr Endocrinol Metab 2013;18:60-4.

11. Cho GJ, Park HT, Shin JH, Hur JY, Kim YT, Kim SH, et al. Age at menarche in a Korean population: secular trends and influencing factors. Eur J Pediatr 2010;169:89-94.

12. Neely EK, Lee PA, Bloch CA, Larsen L, Yang D, MattiaGoldberg C, et al. Leuprolide acetate 1-month depot for central precocious puberty: hormonal suppression and recovery. Int J Pediatr Endocrinol 2010;2010:398639.

13. Neely EK, Hintz RL, Parker B, Bachrach LK, Cohen P, Olney R, et al. Two-year results of treatment with depot leuprolide acetate for central precocious puberty. J Pediatr 1992;121:634-40.

14. Mul D, de Muinck Keizer-Schrama SM, Oostdijk W, Drop SL. Auxological and biochemical evaluation of pubertal 
suppression with the GnRH agonist leuprolide acetate in early and precocious puberty. Horm Res 1999;51:270-6.

15. Carel JC, Lahlou N, Roger M, Chaussain JL. Precocious puberty and statural growth. Hum Reprod Update 2004;10:135-47.

16. Kwon EB, Lee SJ, Cha M, Kim SY. Changes in the predicted adult height after gonadotropin-releasing hormone agonist treatment in girls with idiopathic true precocious puberty. Ann Pediatr Endocrinol Metab 2012;17:160-8.

17. Zachmann M, Sobradillo B, Frank M, Frisch H, Prader A. Bayley-Pinneau, Roche-Wainer-Thissen, and Tanner height predictions in normal children and in patients with various pathologic conditions. J Pediatr 1978;93:749-55.

18. Bar A, Linder B, Sobel EH, Saenger P, DiMartino-Nardi J. Bayley-Pinneau method of height prediction in girls with central precocious puberty: correlation with adult height. J Pediatr 1995;126:955-8.

19. Unrath M, Thodberg HH, Schweizer R, Ranke MB, Binder
G, Martin DD. Automation of bone age reading and a new prediction model improve adult height prediction in children with short stature. Horm Res Paediatr 2012;78:312-9.

20. Lazar L, Padoa A, Phillip M. Growth pattern and final height after cessation of gonadotropin-suppressive therapy in girls with central sexual precocity. J Clin Endocrinol Metab 2007;92:3483-9.

21. Klein KO, Barnes KM, Jones JV, Feuillan PP, Cutler GB Jr. Increased final height in precocious puberty after long-term treatment with LHRH agonists: the National Institutes of Health experience. J Clin Endocrinol Metab 2001;86:47116.

22. Chae HW, Suh I, Kwon AR, Kim YJ, Kim YH, Kang DR, et al. Longitudinal standards for height and height velocity in Korean children and adolescents: the Kangwha study. [corrected]. J Korean Med Sci 2013;28:1512-7. Erratum in: J Korean Med Sci 2013;28:1842. 